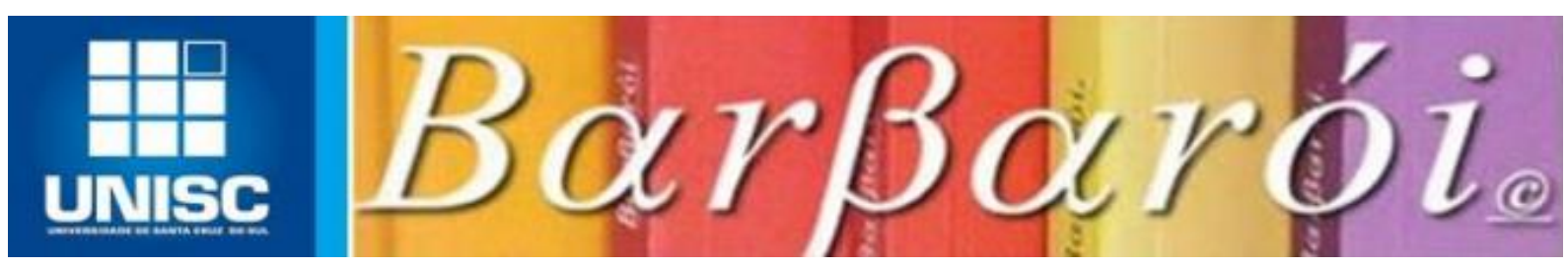

\title{
DISCURSOS E PRÁTICAS PROFISSIONAIS E O ACESSO DE INDÍGENAS À POLÍTICA DE ASSISTÊNCIA SOCIAL
}

\section{DOI: http://dx.doi.org/10.17058/barbaroi.v51i1.11234}

\author{
Maria Carolina da Silveira Moesch \\ Universidade Comunitária da Região de Chapecó - Unochapecó - Brasil \\ Marcia Luiz Pit Dal Magro \\ Universidade Comunitária da Região de Chapecó - Unochapecó - Brasil \\ Dunia Comerlatto \\ Universidade Comunitária da Região de Chapecó - Unochapecó - Brasil
}

\section{RESUMO}

No Brasil, os direitos sociais são previstos pela Constituição Federal de 1988. Do conjunto desses direitos, configuram-se objeto da Política Pública de Assistência Social os direitos a assistência, alimentação, trabalho, proteção à maternidade e à infância, proteção à família, à criança, ao adolescente, ao jovem e ao idoso. Este artigo objetiva analisar os discursos e práticas dos trabalhadores da Política de Assistência Social, considerando quais são os direitos assegurados e quem são os sujeitos de direitos. A pesquisa de campo ocorreu em um município de pequeno porte I do oeste catarinense, marcado pela predominância de população indígena. Utilizou-se a cartografia ao dar ênfase à produção política da subjetividade. Os instrumentos e técnicas para obtenção das informações reuniram observação participante, entrevista cartográfica e rodas de conversa. Há que se considerar os direitos sociais a serem afiançados pela Política de Assistência Social, como o da convivência comunitária e dignidade das pessoas e comunidades. Na busca por assegurar os direitos sociais, mediados pela Assistência Social, percebe-se uma relação de poder que subjuga os sujeitos ao Estado, por meio de tecnologias biopolíticas de controle da vida dos cidadãos. É necessário investir em ações na defesa dos direitos sociais, da autonomia e do protagonismo político e cultural dos usuários da Assistência Social. É urgente e necessário apostar em ações afirmativas protetivas e de fortalecimento dos vínculos familiares e comunitários destinadas à população indígena ou não, de modo a consolidar os Serviços de Proteção Social Básica do Sistema Único de Assistência Social.

Palavras-chave: Assistência Social. População indígena. Biopolítica.

\section{INTRODUÇÃO}

Os direitos sociais - de natureza coletiva, com titularidade individual, assim como os direitos civis e políticos - são fundamentados para resguardar a justiça e a inclusão social, uma vez que decorrem do reconhecimento das desigualdades geradas historicamente pela 
lógica capitalista (COUTO, 2010). De acordo com Bobbio (2004), os direitos sociais são poderes, pois correspondem aos direitos de créditos do indivíduo na relação com a coletividade: a educação, o trabalho, a saúde, a previdência e a Assistência Social.

No Brasil, os direitos sociais são previstos pela Constituição Federal de 1988:

\begin{abstract}
a) Direito à educação; b) Direito à saúde; c) Direito à previdência social; d) Direito à assistência aos desamparados; e) Direito à moradia; f) Direito à Alimentação; g) Direito ao trabalho; h) Direito ao lazer; i) Direito à segurança pública; j) Direito à proteção à maternidade e a infância; k) Direito à cultura; 1) Direito ao desporto; m) Direito à ciência e tecnologia; n) Direito à comunicação social; o) Direito ao meio ambiente; p) Direito de proteção à família, à criança, ao adolescente, ao jovem e ao idoso; q) Direito das comunidades indígenas. (BRASIL, 1988, p. 18).
\end{abstract}

Do conjunto desses direitos, configuram-se objeto da Política Pública de Assistência Social os direitos a assistência, alimentação, trabalho, proteção à maternidade e à infância, proteção à família, à criança, ao adolescente, ao jovem e ao idoso. Paiva (2014) refere que a Constituição Federal de 1988 afirmou a Assistência Social como direito de todas as pessoas, sendo que, com a instituição do Sistema Único de Assistência Social (SUAS), estabeleceu-se um novo projeto voltado à efetiva universalização dos direitos sociais, rompendo com práticas fragmentadas e de tutela, alicerçadas na vertente da subalternização dos usuários dos serviços sociais.

Vianna (1998, p. 142) caracteriza a Seguridade Social como "americanização perversa", pois, segundo sua avaliação, o sistema público tem-se especializado no "mau atendimento de muitos pobres", ao direcionar para contratos cada vez mais seletivos e em quase nada para fortalecer uma lógica estruturante e inclusiva. Couto (2010, p. 161) refere que “[...] a assistência social para explicitar as conquistas dos direitos sociais pela população brasileira é emblemática, pois sua concepção e sua operacionalização revelam os limites e as possibilidades no que concerne à efetivação dos direitos sociais no Brasil.”

Não obstante, muitos têm sido os avanços para romper com a lógica assistencialista e imprimir, cada vez mais, uma lógica de proteção e de defesa de direitos à população usuária, como apontam os estudos de Yazbek (1993), Couto (2010), Monnerat e Souza (2011). Mesmo assim, muitos são os desafios para a consolidação do SUAS, especialmente na atual conjuntura político-econômica vivenciada pelo Estado brasileiro.

Com base nos discursos e práticas de trabalhadores da Política Pública de Assistência Social de um pequeno município do oeste catarinense, é possível traçar uma análise sobre os direitos assegurados, em especial aos indígenas, de modo a considerar quem são esses sujeitos de direitos, o que remete ao objetivo do trabalho ora apresentado. Duas características 
marcam a realidade desse município: concentrar a maior população indígena do Estado; ocupar a terceira posição entre os municípios catarinenses com maior índice de vulnerabilidade e risco social. Isso remete à importância de tecer análises sobre o papel da Política de Assistência Social, reconhecendo o que se apresenta singular nesse território.

A ampla presença de população indígena na região oeste catarinense se soma a esses aspectos, ao evidenciar-se que ainda são poucos os estudos relacionados à região sul do Brasil. Ao se realizarem levantamentos em bancos de dados da Scielo e do Google Acadêmico, com descritores "Política de Assistência Social", "População Indígena", "Suas", "Sul do Brasil”, "Região Sul”, "Índios”, “Assistência Social”, constatou-se que a maior parte das publicações delimita a região norte do País como realidade estudada. A partir desse levantamento, foi possível identificar os estudos de Silva (2012) e Golembieski (2015), que indiretamente tratam da temática "políticas sociais e população indígena"; de Zitzke (2011) e Bringmann (2015), que não focam na Política de Assistência Social.

A noção de "sujeito" toma centralidade nesta discussão, levando em conta a interlocução com Foucault e Agamben para orientar as análises ora apresentadas. Assim, "sujeito", "poder", "biopolítica" e "vida nua" formam o conjunto dos conceitos que são analisados neste artigo. É nessa perspectiva que se pretende cartografar práticas de uma determinada realidade social, econômica e cultural regionalizada do oeste catarinense, a qual constitui subjetividades e produz sujeitos.

A discussão trazida neste artigo remete inicialmente à identificação de como a pesquisa foi organizada em seus procedimentos metodológicos. Na sequência, contextualiza aspectos sobre o município estudado e a gestão da Política de Assistência Social. Dando continuidade, faz referências às visitas domiciliares e institucionais como estratégia de intervenção na oferta de serviços socioassistenciais na área da Assistência Social. O último item de discussão faz referência ao Serviço de Convivência e Fortalecimento de Vínculos (SCFV) como “cartão de visita” dos Centros de Referência em Assistência Social (CRAS).

\section{Procedimentos metodológicos}

Este estudo faz uso do método cartográfico, que busca "[...] desenhar a rede de forças à qual o objeto ou fenômeno em questão se encontra conectado, dando conta de suas modulações e de seu movimento permanente.” (PASSOS; BARROS, 2009, p. 57). A cartografia dá ênfase à produção política da subjetividade, o que implica "[...] uma atenção especial a jogos de verdade e de enunciação, jogos de objetivação e subjetivação, modos de 
sujeição e assujeitamento, produção de corpos morais, sexuais, produtivos, estetizações e produções de si mesmo, formas de resistência, práticas de liberdade [...]” (PRADO FILHO; TETI, 2013, p. 56).

Neste artigo, estão reunidos resultados alcançados pela pesquisa de campo realizada durante o segundo semestre de 2016 na abrangência de um município localizado na região oeste do estado de Santa Catarina. A divisão territorial e administrativa desse município se organiza em 12 comunidades rurais e nove aldeias indígenas - pertencentes à Terra Indígena Xapecó. São 6.798 habitantes, conforme dados do IBGE de 2010, com população estimada em 7.331 habitantes para 2016. Conforme Censo de 2010, concentra a maior população indígena do estado de Santa Catarina, com 3.436 pessoas. Ou seja, 50,54\% do total de seus habitantes são índios, predominantemente da etnia Kaingang, sendo que 79,7\% desse total residem no meio rural, e 63,4\% desses residentes compõem a população indígena. Como município classificado de pequeno porte I pela Política de Assistência Social, enquadra-se no nível da Proteção Social Básica (PSB). Por isso, as ações e os serviços ofertados no âmbito da referida política são executados via CRAS.

Participaram do estudo doze (12) sujeitos, predominantemente a equipe de trabalhadores que atuava na gestão da referida política em 2016: o gestor, com formação em psicologia; um assistente social; três educadores físicos; um trabalhador que desempenhava função administrativa, com formação no ensino médio; dois monitores sociais da pedagogia; dois monitores sociais da educação física; a coordenadora dos idosos do município, que também atua como monitora dos idosos; a técnica de ensino médio, que também compõe a Diretoria de Habitação e auxilia nas atividades dos grupos de convivência e fortalecimento de vínculos.

Os instrumentos e técnicas de pesquisa utilizados foram a observação participante registrada em diário de campo, rodas de conversa e a entrevista cartográfica.

A inserção no cenário da pesquisa possibilitou o processo de observação participante das atividades desenvolvidas pelos trabalhadores da Política de Assistência Social do município pesquisado. Foram realizadas nove visitas ao município, sendo observadas as seguintes atividades: (a) reuniões com a equipe do CRAS; (b) encontros com os usuários da Política de Assistência Social por meio de visitas domiciliares, da participação no SCFV de Crianças, Adolescentes e Idosos, no acolhimento na sala de espera do serviço; (c) reunião realizada pelo Conselho Regional de Psicologia de Santa Catarina (CRP-12), com a participação da Associação Brasileira de Psicologia Social (Abrapso - núcleo Chapecó), 
Conselho Tutelar, Política de Saúde Municipal, lideranças indígenas, Secretaria Municipal de Educação do município estudado.

O diário de campo, ou registro cartográfico, foi utilizado para descrição narrativa dos acontecimentos do campo de pesquisa. Também foi utilizado como instrumento para, após cada visita ao campo de pesquisa, realizar análises do caminho que a pesquisa estava apontando, e aí realizar desvios, novos caminhos ou aprofundar caminhos que se foram desenhando conforme as vivências da pesquisadora no território da pesquisa.

A roda de conversa foi realizada em um encontro junto ao CRAS com a participação de todos os trabalhadores da Política de Assistência Social do município. Já a entrevista cartográfica foi realizada com quatro trabalhadores da Política de Assistência Social, sendo estes do CRAS e do SCFV.

A pesquisa que embasa as discussões contidas neste artigo respeitou as diretrizes da Resolução n. 466/2012 do Conselho Nacional de Saúde, tendo sido aprovada pelo Comitê de Ética em Pesquisa Envolvendo Seres Humanos da Universidade Comunitária da Região de Chapecó (Unochapecó), sob o protocolo CAAE 55891416.0.0000.0116 e número de comprovante 040609/2016.

\section{O município estudado e a gestão da Política de Assistência Social}

Como instrumento de gestão da Política de Assistência Social tem-se o Plano Municipal. O município estudado tem seu plano elaborado para o período de 2014 a 2017, no qual descreve características gerais do contexto local e da população usuária, sobretudo da população indígena. A realidade municipal é marcada por situações consideradas difíceis e complexas de serem enfrentadas, uma vez que "os maiores índices de pobreza do município são encontrados na reserva indígena" (IPUAÇU, 2015, p. 33).

O relatório divulgado em 2016 pela Comissão Econômica para a América Latina (CEPAL), vinculada à Organização das Nações Unidas (ONU), afirma que no Brasil a pobreza extrema afeta seis vezes mais a população indígena do que outras populações (ONUBrasil, 2017). A respeito, o trabalhador da Assistência Social que acompanhou a primeira visita de pesquisa à Reserva Indígena pontua: “[...] agora vamos ver o que é pobreza, pois vamos para a aldeia. Mas eles [os índios] estão acostumados." Tal apontamento sugere, inicialmente, assujeitamento e submissão que se perpetuam em meio a essa população. Considera-se, assim, que o sujeito da Assistência Social está à mercê de uma intervenção que 
produz sujeições por meio de uma maquinaria de racismo do Estado para com a miséria que esse mesmo Estado produz (FOUCAULT a, 2010).

A partir do Censo IBGE de 2010, dados do Instituto de Pesquisa Econômica Aplicada (IPEA, 2017) apresentam os índices de renda e pobreza no município estudado, configurandose uma séria situação de vulnerabilidade social enfrentada na relação com o estado de Santa Catarina, tal qual quadro 1.

Quadro 1 - Índices de renda e pobreza no município estudado em relação ao estado de Santa Catarina

\begin{tabular}{|c|c|c|c|c|c|c|}
\hline Índices & $\begin{array}{c}\mathbf{1 9 9 1} \\
\text { Município }\end{array}$ & $\begin{array}{c}\mathbf{1 9 9 1} \\
\text { SC }\end{array}$ & $\begin{array}{c}\mathbf{2 0 0 0} \\
\text { Município }\end{array}$ & $\begin{array}{c}\mathbf{2 0 0 0} \\
\text { SC }\end{array}$ & $\begin{array}{c}\mathbf{2 0 1 0} \\
\text { Município }\end{array}$ & $\begin{array}{c}\mathbf{2 0 1 0} \\
\text { SC }\end{array}$ \\
\hline $\begin{array}{c}\text { Renda per capita }(\mathrm{em} \\
\mathrm{R} \$\end{array}$ & 170,54 & 449,78 & 292,01 & 693,82 & 530,81 & 983,90 \\
\hline $\begin{array}{c}\text { \% de extremamente } \\
\text { pobres }\end{array}$ & 80,47 & 9,26 & 22,05 & 3,82 & $\mathbf{1 4 , 8 7}$ & 1,01 \\
\hline \% de pobres & 83,98 & 25,32 & 41,73 & 12,79 & $\mathbf{2 7 , 8 6}$ & 3,65 \\
\hline Índice de Gini & 0,87 & 0,55 & 0,53 & 0,56 & $\mathbf{0 , 6 1}$ & 0,49 \\
\hline
\end{tabular}

Fonte: elaboração das autoras, com base no IPEA (2017).

Esse município ocupa a terceira posição no estado catarinense com relação a maior situação de vulnerabilidade e risco social, o que pode ser observado com base no fato de $42,73 \%$ da população se enquadrar como pobre ou extremamente pobre. Associado ao referido percentual, conforma-se o Índice de Gini, instrumento de medição das desigualdades sociais e do nível de concentração de renda. Por esse dado estatístico, pode-se avaliar a distribuição das riquezas de um determinado lugar; o percentual de 0,61 alcançado pelo município estudado mostra desigualdade social maior na relação com o Estado a que pertence.

A incidência dos índices de pobreza nesse município pode ser compreendida no diálogo com a "questão indígena". Conforme a CEPAL, há certa invisibilidade das questões relacionadas aos indígenas e aos afrodescendentes. No documento intitulado "La matriz de la desigualdad social en América Latina", de outubro de 2016, explicita-se:

\footnotetext{
Una de las formas más patentes de exclusión que afecta a la población indígena y afrodescendiente ha sido la invisibilidad estadística de la que tradicionalmente ha sido objeto, lo que significa una vulneración de uno de los principios básicos y fundamentales para el diseño de políticas públicas, como conocer a qué población se dirigen las acciones, dónde se encuentra y cuáles son las necesidades específicas que se están atendiendo o los derechos que se busca garantizar. (CEPAL, 2016, p. 27).
}

Em certa medida, a produção da pobreza que afeta a população indígena no município estudado é determinada pela falta de oportunidade para acessar o mercado de trabalho, pela 
burocracia nos processos e modos de apropriação das terras indígenas historicamente conduzidos em âmbito brasileiro.

No registro cartográfico 5, reconhecem-se as demandas da reserva por meio do que pontuou o cacique, que na ocasião, representava o Conselho dos Caciques do oeste de Santa Catarina, dos Professores da escola indígena e dos Conselhos Tutelares indígenas. Ao tratar da relação "índio e trabalho", afirmou que o acesso ao trabalho lhes é negado e, em decorrência, deixam de ter o direito de acessar a cidade e os empregos, ficando tudo isso reservado ao "não índio".

A dificuldade de acesso ampliado ao mercado de trabalho pela população indígena é reiterada pelos trabalhadores $\mathrm{A}$ e $\mathrm{B}$, que destacam como única alternativa as indústrias de abate e processamento de carnes em municípios circunvizinhos. Sobre isso, o Plano Municipal de Assistência Social (IPUAÇU, 2015, p. 33) registra que

Um dos indicadores sociais preocupantes é a falta de mercado de trabalho no município, fazendo com que a parte mais carente da população tenha que se deslocar a outros municípios em busca de trabalho. Muitos deles vão para as lavouras e colheitas de maçã, erva-mate, feijão, e outros produtos, vivendo como boias-frias, essa realidade é encontrada principalmente na reserva indígena.

O trabalho nas linhas de produção das indústrias de abate e processamento de carnes da região oeste catarinense, conhecidas na região como "agroindústrias", tem gerado adoecimento de parcela dos trabalhadores, como apontam Dal Magro et al. (2013). O trajeto a ser percorrido entre a aldeia do município estudado e as localidades onde as agroindústrias estão instaladas é consideravelmente longo. Isso leva tais trabalhadores indígenas a permanecerem fora de casa por longo tempo em razão do deslocamento, o que acaba ocasionando dificuldades familiares, por exemplo, no cuidado dos filhos.

Além da oferta de trabalho nas agroindústrias, os trabalhadores indígenas se vinculam a atividades na agricultura como diaristas, em terras indígenas ou não indígenas. Nesse sentido, o cacique relata:

[...] falta trabalho, que nem todos acessam trabalhar nos frigoríficos. Fora isso, só a agricultura e a pecuária sobram. [...] aí entra outra questão legal, que as famílias não têm a posse de sítio. Muitas têm só o espaço da casa, alguns ainda têm hortas, mas muitos nem isso têm. (REGISTRO CARTOGRÁFICO N. 5).

Observou-se também durante a pesquisa que a apropriação da terra é muito desigual entre a população indígena das aldeias. As relações de poder e dominação se reproduzem entre os próprios indígenas, gerando desigualdades econômicas e de convívio entre si. 
Associado a isso, está o acirramento da pobreza de uma parcela significativa de famílias pertencentes às aldeias da Terra Indígena Xapecó. Assim, algumas famílias detêm espaços de terra para produzir, outras, porém, somente o espaço onde sua casa está construída, sem a possibilidade de explorar cultivos, inclusive para subsistência do grupo familiar.

Sobre isso, Kujawa (2005, p. 159) refere que a população Kaingang (mais que outras populações indígenas) pratica o arrendamento de terras para o plantio da monocultura extensiva da soja, o que tem propiciado a "apropriação de grande parte das áreas por algumas lideranças indígenas", de modo ilícito e desfavorável economicamente para uma grande maioria. $\mathrm{O}$ que refere o autor pôde ser observado durante as visitas realizadas nas aldeias: de um lado, a existência de grande extensão de terra cultivada; de outro, parcela da população indígena concentrada em áreas centrais, evidenciando condições precárias de permanência. Observou-se que, sobre essa questão envolvendo "a demarcação e posse de terras entre indígenas", há desconhecimento por parte dos trabalhadores que atuam na Política de Assistência Social do município estudado, mesmo a população indígena sendo a maior demanda de trabalho dessa política.

Evidências durante o estudo realizado levam a identificar que o valor recebido via Programa Bolsa Família (PBF), do Governo Federal, consistia na única fonte de renda para muitas das famílias beneficiadas, incluindo aqui grande parte da população indígena do município. Apesar de assegurarem mínimos valores, essas ações promovem o acesso a uma renda mensal, salvaguardando o direito à renda, previsto no Decálogo dos Direitos Socioassistenciais, aprovado em 2005, durante a V Conferência Nacional de Assistência Social:

Direito, do cidadão e cidadã e do povo indígena, à renda individual e familiar, assegurada através de programas e projetos intersetoriais de inclusão produtiva, associativismo e cooperativismo, que assegurem a inserção ou reinserção no mercado de trabalho, nos meios urbano e rural.

Pereira e Guareschi (2013) apontam que, de um lado, a Política de Assistência Social pode melhorar, mesmo que minimamente, situações de déficits que afetam indivíduos e grupos familiares, ao assegurar o acesso a serviços em defesa de direitos e ao promover processos de inclusão social; de outro, por meio da garantia de mínimos sociais, pode paralisar ou amenizar a luta de indivíduos e grupos por alterações mais profundas e transformadoras da "dura" realidade social vivida. 
Esse paradoxo apontado pelos autores pode ser analisado como um engendramento perverso da lógica capitalista, que se utiliza dos mecanismos da individualização de problemáticas, paralisando os processos coletivos para uma lógica de transformação social. Faz-se, assim, uma "gestão da pobreza", com ações compensatórias e reparadoras, que tradicionalmente têm inibido o alcance de processos alterativos e emancipatórios, de modo a ampliar e defender os direitos e a justiça social.

\section{As visitas domiciliares: estratégia de intervenção na oferta dos serviços socioassistenciais}

Nos cadernos da "Tipificação dos Serviços Socioassistenciais", a visita domiciliar, vinculada à Proteção Social Básica, é entendida como estratégia de intervenção para desenvolver atividades do Serviço de Proteção e Atendimento Integral à Família (PAIF), nas formas de acesso da população, e podendo ser realizada pela busca ativa (BRASIL, 2009). O PAIF consiste no trabalho social com famílias, “[...] de caráter continuado, com a finalidade de fortalecer a função protetiva das famílias, prevenir a ruptura dos seus vínculos, promover seu acesso e usufruto de direitos e contribuir na melhoria de sua qualidade de vida." (BRASIL, 2009, p. 12).

Relacionado ao nível de Proteção Social Básica, o Plano Municipal de Assistência Social do município estudado indica que, na operacionalização do PAIF, as visitas domiciliares e institucionais ${ }^{1}$ - ao atingir um público de 3.500 pessoas, aproximadamente 1.500 famílias - configuram de modo intenso a intervenção realizada pelos trabalhadores da referida política pública. Associadas às visitas domiciliares, estão as visitas institucionais, que buscam a interlocução entre a política municipal de Assistência Social e a Justiça, caracterizando não só uma grande demanda de trabalho mas também a intervenção na comunidade.

Em todas as inserções no contexto da pesquisa de campo, a visita domiciliar se constituiu numa prática recorrente, sendo possível identificar as situações que mais as demandaram: alcoolismo; negligência na atenção às pessoas idosas; intimação judicial às famílias, relacionada a membros crianças e adolescentes. Essas situações, em sua maioria, deveriam ser atendidas pelos serviços vinculados à Proteção Social Especial de Média e Alta Complexidade do Sistema Único de Assistência Social (SUAS) (REGISTROS CARTOGRÁFICOS N. 2, 3, 7).

\footnotetext{
${ }^{1}$ Sobre as visitas institucionais, o Plano Municipal de Assistência Social 2014-2017 não faz qualquer referência.
} 
Destaca-se que a maioria dessas visitas se destina à população das aldeias da Terra Indígena Xapecó. Registram-se a seguir aspectos da primeira inserção, do primeiro impacto e do estado de exceção de uma vida nua:

\begin{abstract}
Descemos do carro, e com muita dificuldade conseguimos entrar na peça onde estava o senhor acamado. A casa de madeira com grandes frestas ficava no meio de um barranco, e para chegar nela havia apenas uma escada talhada na própria terra. Ao chegar na casa de dois cômodos percebemos que um era a cozinha, sala e quarto onde moravam o casal e dois filhos, e o outro cômodo, um pequeno quarto com uma cama de pau a pique, onde estava o pai da senhora que nos chamou. Noventa anos, magro, num colchão velho e muito fino para o frio que fazia. Não falava. (REGISTRO CARTOGRÁFICO N. 2).
\end{abstract}

Era um espaço muito pequeno; a solicitação da pessoa que parou o carro da Assistência Social na rua era para conseguir uma cadeira de rodas, que pudesse facilitar a entrada do idoso ao banheiro, e um colchão novo, mas que fosse um colchão de água, em função do tempo que o idoso permanecia acamado. Ao olhar-se para o banheiro - longe da casa, uma espécie de "capunga" ou "patente", como nomeado na região -, restava a certeza de que, mesmo com uma cadeira de rodas, seria impossível para aquele idoso adentrar no banheiro.

Agamben (2010, p. 91) fala da sacralidade da vida ao realizar uma crítica aos direitos humanos: “[...] a sacralidade da vida, que se desejaria hoje fazer valer contra o poder soberano como um direito humano em todos os sentidos fundamental, exprime, ao contrário, justamente a sujeição da vida a um poder de morte, a sua irreparável exposição na relação de abandono." O abandono pela condição de pobreza expressa a situação da família visitada.

Abandono parecia a "frase do dia" na segunda inserção no campo. Logo que saímos da primeira visita não agendada, mais uma visita não agendada surgiu em frente ao "carro da Assistência Social" que nos conduzia. Mais uma visita, mais uma pessoa que aparentava ser idosa, mais um indígena, mais uma vida nua:

Estávamos nos dirigindo [pesquisador, e dois trabalhadores do CRAS do município], já com curiosidade para conhecer a escola em forma de oca e o ginásio de esportes em forma de tatu, quando avistamos um senhor. A profissional que nos acompanha então pede para que paremos para que ela veja como ele está, pois há poucos dias ela e o motorista tinham trazido a mudança dele de Chapecó. Disse que ele andava pelas ruas de Chapecó, como andarilho, e que o serviço de resgate social descobriu que ele tinha um filho em uma das aldeias do município. Quando da chegada ao município, este filho não quis acolher o pai, o que foi realizado por um vizinho. O vizinho construiu uma peça de mais ou menos um metro por um metro meio onde havia uma cama, um sofá de dois lugares, já sem forro, e espuma, um fogão quatro bocas, com muito resto de comida estragada para todos os lados. Em cima da cama, estava o que parecia ser a roupa deste senhor e suas cobertas, todas juntas amontoadas. O senhor diz ter 58 anos, mas aparenta ter bem mais. (REGISTRO CARTOGRÁFICO N. 2). 
Os quadros descritos nesses registros revelam que, embora essa população acesse mínimos sociais [no caso da renda] outras necessidades estão distantes de ser alcançadas. Para Corrêa (2014), os direitos humanos, genealogicamente, apontam para uma vida humana capturada por intermédio de seu abandono à morte na relação de exceção soberana, ou seja, implicam uma antropologia evanescente, que só serve à soberania, não ao povo.

Durante essas inserções, foi possível entender o que os trabalhadores dizem ao indicarem que a maior demanda de trabalho está direcionada para as aldeias indígenas e ao indicarem a importância que as visitas domiciliares têm para localizar situações novas, de modo que a inclusão e o acesso aos direitos possam ser trabalhados no âmbito da Política de Assistência Social e outras afins.

Assim, de maneira individualizada e em várias situações individualizantes dos processos vivenciados pelas famílias é que se caracterizam as visitas domiciliares no município, sem que se tenha uma equipe técnica responsável pelo PAIF. As ações ocorrem como um "desvio de função" dos trabalhadores da Política de Assistência Social. Sem recursos humanos referenciados à função - na perspectiva do trabalho do PAIF e na lógica de intervenção especializada de média e alta complexidade -, as ações ocorrem de modo individualizado - deixando de atingir o núcleo familiar. Assim, garantem-se parcialmente as seguranças afiançadas pela Assistência Social por meio da prestação desse serviço: segurança do convívio familiar e comunitário; e segurança do desenvolvimento da autonomia, do convívio à acolhida.

Entende-se que a visita domiciliar alcança parcialmente seus objetivos, pois, ainda que de modo precarizado, por não se ter uma equipe técnica de referência e pela restrição dos serviços ofertados, possibilita o acesso às ações socioassistenciais - por meio do Cadastro Único, dos Programas de Transferência de Renda, do Serviço de Convivência e Fortalecimento de Vínculos (SCFV) e do Serviço de Proteção Social Básica no Domicílio para Pessoas com Deficiência e Idosas.

Considerando que as visitas domiciliares acontecem quase que exclusivamente em razão das situações caracterizadas complexas, exigindo atendimento especializado, a Assistência Social se coloca paliativa em suas ações, predispondo a população a situações de exclusão, uma exclusão cuja análise não é "um estado que se adquire ou do qual se livra em bloco de forma homogênea", mas como processo complexo, “[...] configurado nas confluências entre o pensar, o sentir e o agir e as determinações sociais mediadas pela raça, classe, idade e gênero.” (SAWAIA, 2001, p. 110). 
Consideram-se as visitas domiciliares como uma lupa para o reconhecimento do que, aqui, optou-se por chamar de "violências permitidas pelo Estado", para humanos de vida nua. E só com essa lupa carregada de realidade é que se podem pensar estratégias para que o próprio fundamento dos direitos humanos possa se tornar uma estratégia de contrapoder e resistência (CORRÊA, 2014).

Em síntese, e corroborando com Agamben (2004), esse é o sujeito, "vida nua", aqui público da Política da Assistência Social, caracterizado de modo individual por meio das visitas domiciliares, em seus territórios. Um sujeito que nesse território constituirá a vida nua, apartada da condição de humano, para o qual os direitos humanos nem sempre chegam. A ele, resta o estado de exceção, que Agamben (2004) apresenta como uma abertura de um espaço em que a aplicação e a norma mostram sua separação.

Agamben (2010) traz essa discussão para a atualidade ao constatar que, em determinadas camadas da população, as pessoas são expostas à morte pelo governo, vivendo em estado de exceção. Para tanto, retomam-se os estudos de Foucault (1926-1984) e Hannah Arendt (1906-1975), especialmente a noção de "biopolítica" de Foucault e os estudos de Hannah Arendt (2010, p. 11) sobre o processo que leva o homem biológico a ocupar progressivamente o "centro da cena política do moderno".

Para realizar tal estudo, Agamben (2010) apresenta a noção de "vida nua", termo inventado por Hannah Arendt em Origens do Totalitarismo, de 1951. Na obra, a autora usa a expressão para identificar os homens que, no período entreguerras, perdiam o direito a ter direitos e, portanto, encontravam-se excluídos da própria noção de "humanidade", dada a desnacionalização em massa que ocorreu no período (CORRÊA, 2014).

Ao apresentar o conceito de "vida nua", Agamben (2010) aprofunda-o para além da concepção de Arendt sobre os apátridas, trazendo-o para a atualidade:

\footnotetext{
Desse modo, a união impossível entre norma e realidade, e a consequente constituição do âmbito da norma, é operada sob a forma da exceção, isto é, pelo pressuposto da relação. Isso significa que, para aplicar uma norma, é necessário, em última análise, suspender sua aplicação, produzir uma exceção. Em todos os casos, o estado de exceção marca um patamar onde a lógica e a práxis se indeterminam e onde uma pura violência sem logos pretende realizar um enunciado sem nenhuma referência real. (AGAMBEN, 2010, p. 63).
}

O estado de exceção para um povo de vida nua é a realidade social encontrada no município estudado, com alguns ensaios voltados a práticas emancipatórias, como a situação descrita anteriormente. E o importante é isso, que esse novo momento foi iniciado num diálogo do sujeito com os direitos intermediados pela Política de Assistência Social e seu 
novo caráter, a partir da Constituição Federal de 1988: de ser uma política pública no campo da Seguridade Social brasileira.

\section{O Serviço de Convivência e Fortalecimento de Vínculos (SCFV): o "cartão de visita"}

Segundo a Tipificação Nacional dos Serviços Socioassistenciais (BRASIL, 2009), o Serviço de Convivência e Fortalecimento de Vínculos (SCFV) corresponde às atividades realizadas em grupo, de acordo com o ciclo de vida dos usuários, cuja finalidade está em complementar o trabalho social com famílias, prevenindo a ocorrência de situações de risco social. Com essa finalidade, o SCFV

\footnotetext{
Organiza-se de modo a ampliar trocas culturais e de vivências, desenvolver o sentimento de pertença e de identidade, fortalecer vínculos familiares e incentivar a socialização e a convivência comunitária. Possui caráter preventivo e proativo, pautado na defesa e afirmação dos direitos e no desenvolvimento de capacidades e potencialidades, com vistas ao alcance de alternativas emancipatórias para o enfrentamento da vulnerabilidade social. (BRASIL, 2009, p. 16).
}

De acordo com o Plano Municipal de Assistência Social (IPUAÇU, 2015) do município estudado, o SCFV está direcionado a aproximadamente 959 pessoas. Contudo, o número de pessoas que frequentam os grupos promovidos por esse serviço se mostrou bem menor; conforme os diários cartográficos realizados nas visitas de acompanhamento aos grupos dos SCFV de crianças, adolescentes e idosos usuários, nenhum deles reuniu mais de 30 participantes. E, ainda, a infraestrutura física disponível e utilizada evidencia uma incapacidade de acolhida do número de pessoas referidas no plano, haja vista que as atividades acontecem no Centro de Múltiplo Uso ou na própria sede das aldeias, uma vez que no CRAS não há espaço para tal.

Conforme informações obtidas dos trabalhadores (REGISTRO CARTOGRÁFICO N. 2), o SCFV é o maior serviço oferecido pela Política de Assistência Social, sendo que, na composição da equipe, educadores físicos e monitores de artesanato são a maioria. Associados a esses trabalhadores, estão eventualmente os técnicos psicólogos e assistentes sociais, para atender uma população considerada como a mais vulnerável socialmente, formada por crianças, adolescentes e idosos.

Como objetivo, o SCFV pretende "[...] o desenvolvimento de ações intergeracionais e a heterogeneidade na composição dos grupos por sexo, presença de pessoas com deficiência, etnia, raça, entre outros." (BRASIL, 2009, p. 16). Entretanto, as atividades desenvolvidas 
tanto com os idosos quanto com as crianças e adolescentes são realizadas em separado no território de abrangência. Ainda, são limitadas no sentido de promover a integração e a interculturalidade, e acontecem com igual teor envolvendo "índios" e "não índios".

Fica evidente, pelos registros cartográficos e pelas observações realizadas (especialmente os registros 2, 3 e 4), que a população indígena está, e muito, presente nos discursos dos trabalhadores. Contudo, as ações que poderiam preservar e acolher a sua diversidade cultural inexistem. Assim, torna-se necessário promover práticas que superem a invisibilidade (ainda forte) da população indígena, em respeito e valorização aos modos e costumes diversificados culturalmente, pois o que se percebe são a aculturação e a sujeição do usuário indígena no contexto do município estudado.

Sobre isso, registra-se a reflexão de Foucault (1995) ao afirmar que, no século XIX, a luta contra exploração assumiu o primeiro plano e, na atualidade, o primeiro plano das lutas sociais se põe contra as formas de sujeição, contra a submissão da subjetividade. Coloca-se, assim, a necessidade de se concretizarem "lutas", como potência para a Política de Assistência Social, em especial para o município estudado.

Esses movimentos de aculturação e sujeição reproduzidos pela gestão municipal da Política de Assistência Social podem ser observados, por exemplo, pelas atividades "festa junina" e "cultos religiosos católicos" desenvolvidas nos SCFVs com crianças e adolescentes. Isso reforça a invisibilidade do que é particular da cultura dos povos indígenas, não somente pela via da Assistência Social, mas também pela Educação e Saúde.

\footnotetext{
Perguntei [pesquisador] como era a questão da diversidade cultural, pois o espaço estava todo enfeitado para a festa junina - e não conhecia como os indígenas dialogam com a questão desta festividade, que está recheada de crenças específicas, em especial religiosas. Elas [as monitoras dos SCFVs] responderam que para eles [indígenas] era normal, já fazem e participam na escola, então já estão acostumados. (REGISTRO CARTOGRÁFICO N. 2).
}

A Constituição Federal de 1988, em seu art. 231, reconhece os índios como cidadãos diferenciados, cuja organização social, costumes, crenças e línguas devem ser respeitados. Nessa lógica, o Ministério de Desenvolvimento Social e Combate à Fome elaborou um documento de referência para o atendimento aos povos indígenas pela Assistência Social, intitulado "Trabalho Social com Famílias Indígenas - proteção social básica para uma oferta culturalmente adequada": 
nesse sentido que o Estado brasileiro vem tentando construir políticas públicas sensíveis às especificidades indígenas [...]. Sendo assim, a atuação dos técnicos deve ser pautada pelo respeito à diferença como direito assegurado aos povos indígenas. O CRAS deve ser a porta de entrada destes cidadãos ao SUAS. (BRASIL, 2016, p. $8)$.

Muito embora garantido constitucionalmente, o atendimento à população indígena não tem respeitado a diversidade cultural, tampouco promovido autonomia e reflexões na perspectiva de um trabalho social por meio dos SCFVs em funcionamento no município estudado. Isso pode ser observado, por exemplo, junto às idosas indígenas que participam do SCFV, considerando que, durante a observação realizada, passaram boa parte da tarde realizando trabalho manual de macramê e crochê. Logo na chegada ao local em que estavam reunidas, viam-se as índias produzindo bordado com agulha de costura e fios de linha. "Olhando as mãos das senhoras, bem idosas, trêmulas, realizando um trabalho tão minucioso [...], pensa-se 'que sentidos produzem esse encontro?' Elas estavam em silêncio, fazendo, desfazendo e refazendo, forçando olhos e mãos numa tarefa manual." (REGISTRO CARTOGRÁFICO N. 2).

Para Foucault (1995, p. 236), “[...] todos os tipos de sujeição são fenômenos derivados, que são meras consequências de outros processos econômicos e sociais: forças de produção, luta de classe e estruturas ideológicas que determinam a forma de subjetividade." Portanto, a sujeição e seus mecanismos de assujeitamento, como o modo de organização dos grupos de idosos por meio do SCFV no município estudado, não podem ser estudados distanciados de sua relação com os mecanismos de exploração e dominação.

Trata-se, pois, do sujeito e do seu acesso aos direitos sociais, do engendramento desses direitos nas lógicas que constituem outras possibilidades na contramão desses mecanismos de assujeitamento e sujeição (FOUCAULT, 1995). É o que Agamben trata como estado de exceção, uma vez que essa conversão de súdito para cidadão [de direitos] produz a implicação da vida em novos dispositivos de subjetivação, ao mesmo tempo que produz sua exclusão social (CORRÊA, 2014).

Sobre as atividades do SCFV realizadas com crianças e adolescentes, desde a primeira visita, chamou a atenção a que estava sendo conduzida: crianças e adolescentes indígenas dançando uma música de estilo Pop com a educadora física; outros apenas olhando, por não gostarem do estilo musical ou por não ser permitido participar em função da religião. Sobre isso, consta relatado em diário cartográfico: 
Haviam cinco meninos sentados, olhando as meninas dançar. E uma educadora física ensaiando uma música com seis meninas. As outras três meninas estavam em um banco. Quando entramos, cumprimentamos todos e sentamos ao lado das meninas que estavam no banco [...] pergunto para as meninas ao meu lado: "Porque vocês não estão dançando, participando da atividade?" Uma delas me diz falando por todas: "Não podemos, pois somos crentes!" Faço sinal de afirmativo com a cabeça. (REGISTRO CARTOGRÁFICO N. 3).

Há uma média de 605 crianças e adolescentes de 0 a 17 anos participando no SCFV no município estudado - uma população que desde a infância vivencia uma trajetória de subordinação, sujeição e de resignação a essa condição, constituindo um modo de assujeitamento produtor de subjetividades. O Entrevistado C expressa a respeito: “[...] eu penso assim: que eles são mais compreensivos com a gente [referindo-se às crianças e adolescentes indígenas], quando você diz uma coisa, eles obedecem."

$\mathrm{O}$ mesmo Estado, que por meio da função interposta à Assistência Social busca o acesso aos direitos socioassistenciais ao seu público-alvo, relega ao sujeito o lugar da vida nua, através das suas tecnologias biopolíticas de controle do homem, que não "alcança o status" de cidadão, sendo, nesta perspectiva, considerado o novo morto vivente, um novo homem sacro. E a biopolítica moderna é que, em seus dispositivos, busca "[...] redefinir continuamente, na vida, o limiar que articula e separa aquilo que está dentro daquilo que está fora.” (AGAMBEN, 2010, p. 127). A estrutura dessa biopolítica é que decide o dentro e o fora, o valor da vida como tal.

\footnotetext{
Ao contrário da transformação dos índios em "civilizados" integrados à sociedade nacional, a ação estatal atualmente deve reconhecer e respeitar as línguas indígenas, as identidades étnicas dos seus falantes e as diferentes formas de organização social e visões de mundo dos povos nativos do Brasil. Para eles, o direito à autodeterminação é primordial. Seu reconhecimento implica respeitar e acatar os pontos de vista das diferentes nações indígenas: oportunizar espaços de escuta e ouvir suas definições sobre o trabalho social que desejam. (BRASIL, 2016, p. 9).
}

Nessa perspectiva, no âmbito do município estudado, há que se estabelecer uma agenda de trabalho, inicialmente pela gestão da Política de Assistência Social, de modo a incentivar e promover a mobilização das lideranças e organizações representativas em meio às aldeias indígenas, buscando - além da proteção social em face das vulnerabilidades e dos riscos sociais que enfrentam - o fortalecimento de suas famílias e comunidades na revitalização de suas tradições culturais.

Há que se considerar, ainda, os direitos sociais a serem afiançados pela Política de Assistência Social, como a convivência comunitária e a dignidade das pessoas e comunidades, em relação ao que o SCFV cumpriria função protagonista. No tocante ao município estudado, 
na regra, essa função tem sido promovida pelas igrejas que se fazem presentes nas aldeias. Durante a pesquisa, observou-se a presença de inúmeras igrejas pentecostais em todas as aldeias. "Nossa, ali no Pinhalzinho [referindo-se à aldeia que fica mais próxima à cidade, localizada às margens da rodovia que atravessa a cidade] deve ter umas 30 igrejas [...]" (ENTREVISTADA B). Analisa-se a igreja (ou as igrejas) como um dispositivo, um dos fios condutores na delimitação e organização político-administrativa dos territórios indígenas na abrangência do município estudado.

Em atividade realizada durante a pesquisa de campo que contou com a participação de várias lideranças indígenas, foram ouvidos relatos afirmando o papel das igrejas como muito importante ao agregar jovens em trabalhos de grupos, inibindo situações de rua e de aproximação com drogas. Igualmente, as igrejas têm desenvolvido trabalhos com as crianças, o que é considerado positivo e uma forma de prestar assistência às comunidades indígenas (REGISTRO CARTOGRÁFICO N. 5).

Entre retrocessos e sujeição, é possível visualizar, em certa medida, o papel estimulador dessas igrejas no que se refere às ações de convivência e de apoio comunitário para fortalecer a população e as comunidades indígenas em sua capacidade organizativa contribuindo e tomando para si o papel político a ser construído e produzido pela Política Municipal de Assistência Social, essencialmente pelas ações de Proteção Social Básica. Sobre isso, resta um questionamento: como essa relação pode produzir subjetividades, coletividades e assegurar direitos constitucionalmente garantidos considerando que muitas das atividades realizadas pelas igrejas podem se caracterizar como favor, assistencialismo, benesse ou tutela? Assim, o status de sujeito de direitos não é alcançado, tampouco se consolida em meio às relações sociais estabelecidas entre população indígena e não indígena no contexto do município estudado.

\section{Considerações finais}

Considerando que a pesquisa de campo desenvolvida no município estudado não contemplou a escuta direta da população (indígena e não indígena), mas sim a participação da pesquisadora nas ações cotidianas realizadas pela área da Assistência Social, foi possível conhecer, observar e refletir sobre a realidade "vivenciada" por meio do uso do método cartográfico. A cartografia possibilitou enveredar por novos caminhos, conhecendo a realidade das aldeias da Terra Indígena Xapecó e gerando aproximação das discussões que 
atualmente o Conselho Regional de Psicologia (CRP-12) ${ }^{2}$ do estado de Santa Catarina tem estabelecido a respeito do diálogo entre direitos humanos, povos indígenas e psicologia.

Com as noções de "sujeito", "poder" e "biopolítica", foi possível compreender, de um lado, um território de sujeição, de controle, em que a função da Política de Assistência Social se caracteriza pela "gestão da pobreza"; de outro, que tais noções são potencializadoras de novos modos de resistências.

Compreende-se que a Política de Assistência Social trabalha com sujeitos de vida nua, sujeitados ao controle biopolítico do Estado pelo dispositivo da governamentalidade. Esse dispositivo biopolítico de controle e essa vida nua foram aqui materializados por meio dos diversos discursos dos trabalhadores da Política de Assistência Social no município estudado, os quais teciam os acontecimentos e agenciavam sujeitos e territórios nesse âmbito de intervenção profissional. O sujeito usuário dessa política ainda é um sujeito-sujeitado, de vida nua, sob a batuta do Estado como agente que "o faz viver e o deixa morrer". A esse sujeito, é dada a direção da vida, sem que possa ele mesmo refletir e criar novos caminhos.

Nacionalmente, a Política de Assistência Social teve avanços com a implantação do Sistema Único de Assistência Social (ainda que a passos lentos) no sentido do acesso aos direitos sociais. No município estudado, reconhece-se especialmente o direito à proteção à família, à criança, ao adolescente e ao idoso, ao considerar-se a oferta com maior ênfase, tanto para a população indígena como não indígena, dos Serviços de Convivência e Fortalecimento dos Vínculos. A importância da oferta desse serviço é reconhecida pelos seus trabalhadores, mesmo diante das dificuldades operacionais existentes.

O direito de assegurar renda (ainda que mínima) também faz parte dos discursos desses trabalhadores. Como programa de transferência de renda, mantido exclusivamente pelo Governo Federal, o Bolsa Família tem sofrido cortes orçamentários significativos, resultando no não acesso a ele, e no aumento de situações de vulnerabilidade e risco social; esse contexto atinge tanto a população indígena quanto a não indígena no contexto do município estudado.

Na busca por se assegurar direitos sociais, mediados pela Assistência Social, percebese ainda uma relação de poder que subjuga os sujeitos ao Estado, por meio de tecnologias biopolíticas de controle da vida dos cidadãos (FOUCAULT, 1995). É visível o quanto ainda é necessário apostar e investir em ações em defesa dos direitos sociais, da autonomia política e cultural dos usuários.

\footnotetext{
${ }^{2}$ Em reunião ocorrida no dia 09 de março de 2017, decidiu-se pela realização do Primeiro Seminário Estadual de Psicologia, Povos Indígenas e Direitos Humanos, influenciado pela aproximação deste estudo com as questões indígenas até aqui descritas.
} 
Em muitos momentos da pesquisa de campo houve a necessidade de se centrar no autor do discurso. Isso, para compreender o que do seu próprio discurso reproduzia um discurso maior, do coletivo, que classifica e ordena, distribui e exerce controle sobre os sujeitos de direitos da Política Municipal de Assistência Social. Expressam-se, assim, mecanismos de controle e sujeição, como quando, por exemplo, desenvolviam-se atividades de modo impositivo: não era uma construção coletiva do grupo, mas a necessidade de realizar uma ação considerada de Assistência Social - no caso, o artesanato (FOUCAULT, 1995).

Todavia, existem movimentos na contramão desse controle biopolítico, em algumas pequenas ações. Nesse sentido, podemos acenar para os documentos e normativas que apontam ao respeito à diversidade cultural, nesse caso, da população indígena. Trata-se de um avanço na superação da sua invisibilidade para as políticas públicas operacionalizadas nos âmbitos municipal e nacional.

É notável o quanto o Sistema Único de Assistência Social organiza e orienta as ações nesse campo de trabalho. Muitas são as conquistas. Uma delas é o espaço do Centro de Referência de Assistência Social para promover a proteção social básica, considerado pela população um local de referência - a porta de entrada e a segurança de acolhida, especialmente em municípios de pequeno porte I. Associadamente às conquistas operacionais, permanecem desafios no sentido de efetivar ações com potencial emancipatório. Como estabelecimento de referência socioassistencial, o referido CRAS se posiciona como um agente mediador entre as diversas políticas públicas municipais, capaz de acionar e integrar a oferta de ações para a consolidação da rede socioassistencial.

Durante a inserção no campo de pesquisa, alguns aspectos chamaram nossa atenção para novos estudos: um deles se refere à questão dos indígenas e do trabalho nas indústrias de abate e processamento de carnes na região; outro diz respeito aos trabalhadores da Assistência Social, afetados por situações contratuais temporárias - ou seja, geradoras de instabilidade funcional, pois, a cada final de ano, monitores sociais e educadores físicos são desligados do trabalho na Assistência Social. Ocorre, assim, baixo investimento em novas ações e na qualificação das condições de oferta dos serviços de proteção social.

Sem dúvida, é urgente e necessário apostar em ações afirmativas protetivas e de fortalecimento dos vínculos familiares e comunitários destinadas à população indígena ou não, de modo a consolidar os Serviços de Proteção Social Básica do Sistema Único de Assistência Social no contexto do município estudado. 


\title{
DISCOURSE AND PROFESSIONAL PRACTICES AND INDEGENOUS PEOPLE ACESS TO POLITICS AND SOCIAL ASSISTENCE
}

\begin{abstract}
In Brazil, social rights are established by the Federal Constitution of 1988. Of all these rights, rights of assistance, food, work, maternity and child protection, protection of the family, child, adolescent, young and old. This article aims to analyze the speeches and practices of the workers of the Social Assistance Policy, considering what the rights are assured and who the subjects of rights are. The field research was carried out in a small municipality of the west of Santa Catarina, marked by the predominance of indigenous population. Cartography was used to emphasize the political production of subjectivity. The instruments and techniques for obtaining the information gathered participant observation, cartographic interviews and conversations with locals. It must be considered the social rights to be guaranteed by the Social Assistance Policy, such as the community coexistence and dignity of people and communities. In the quest to secure social rights, mediated by Social Assistance, we perceive a power relationship that subjugates subjects to the State, through bio political technologies to control citizens' lives. It is necessary to invest in actions in the defense of social rights, autonomy and political and cultural protagonism of Social Assistance users. It is urgent and necessary to invest in affirmative and protective actions and the strengthening of family and community ties aimed at the indigenous population or not, in order to consolidate the Basic Social Protection Services of the Single Social Assistance System.
\end{abstract}

Keywords: Social Assistance. Indigenous Population. Bio politics

\section{REFERÊNCIAS}

AGAMBEN, G. Estado de exceção: Homo Sacer II. v. I. São Paulo: Boitempo, 2004.

Homo Sacer: o poder do soberano e a vida nua. Tradução de Henrique Burigo. 2. ed. Belo Horizonte: UFMG, 2010.

ALMEIDA, A. C. O empoderamento de lideranças indígenas Kaingang no sul do Brasil. Interações, Campo Grande, v. 16, n. 2, p. 407-419, jul./dez. 2015.

BOBBIO, N. A era dos direitos. 7. reimpr. Rio de Janeiro: Elsevier, 2004.

BRASIL. Constituição (1988). Constituição da República Federativa do Brasil. Brasília, DF: Senado Federal, 1988.

Orientações Técnicas. Trabalho social com famílias indígenas: proteção social básica para uma oferta culturalmente adequada. Brasília, 2016.

Política Nacional de Assistência Social (PNAS). Brasília, 2004.

Tipificação Nacional de Serviços Socioassistenciais. DOU, Brasília, DF, 2009. 
BRINGMANN, F. S. Entre os índios do Sul: uma análise da atuação indigenista do SPI e de suas propostas de desenvolvimento educacional e agropecuário nos postos indígenas Nonoai/RS e Xapecó/SC (1941-1967). 2015. 452 f. Tese (Doutorado em História)Universidade Federal de Santa Catarina, Florianópolis, 2015.

CÂMARA DOS DEPUTADOS. Portaria n. 792/2007 de 20 de abril de 2007. Brasília, 2007.

CEPAL - COMISSÃO ECONÔMICA PARA A AMÉRICA LATINA E O CARIBE. La matriz de la desigualdad social en América Latina. Octubre de 2016. Original: Español S.16-00946. Naciones Unidas. Impreso en Santiago.

CNS - CONSELHO NACIONAL DE SAÚDE. Resolução CNS n. 466/2012. Regulamenta a pesquisa com seres humanos no Brasil. Brasília, 2012.

CORREAA, M. D. C. Biopolítica e direitos humanos: Giorgio Agamben e uma antropologia evanescente. Profanações, Mafra, ano 1, n. 1, p. 22-37, jan./jun. 2014.

COUTO, B. O direito social e a Assistência Social na sociedade brasileira: uma equação possível? 4. ed. São Paulo: Cortez, 2010.

DAL MAGRO, M. L. P.; COUTINHO, M. C.; MORÉ, C. L. O. O. O obscurecimento da dor como dispositivo de controle da força de trabalho frente às LER/Dort: o caso das indústrias de abate e processamento de carnes. Universitas Psychologica, Bogotá, v. 12, n. 4, p. 1195-1209, 2013.

FOUCAULT, M. Em defesa da sociedade: curso no Collège de France (1975-1976). Tradução de Maria Ermantina Galvão. 2. ed. São Paulo: WMF Martins Fontes, 2010a.

Nascimento da biopolítica. Tradução de Pedro Elói Duarte. Lisboa: 70, 2010 b.

O sujeito e o poder. In: DREYFUS, H.; RABINOW, P. Uma trajetória filosófica: para além do estruturalismo e da hermenêutica. Rio de Janeiro: Universitária, 1995. p. 231249.

GOLEMBIESKI, C. O PAA, política social e povos indígenas: um estudo de caso do Programa de Aquisição de Alimentos no Município de Ipuaçu - SC. 2015. 135 f. Dissertação (Mestrado em Desenvolvimento Regional) - Universidade Tecnológica Federal do Paraná, Pato Branco, 2015.

IBGE - INSTITUTO BRASILEIRO DE GEOGRAFIA E ESTATÍSTICA. Uma análise dos resultados do universo do censo demográfico de 2010. Rio de Janeiro: IBGE, 2011.

IPUAÇU. Prefeitura Municipal. Plano Plurianual de Assistência Social: 2014-2017. Ipuaçu, SC, jun. 2015.

IPEA - INSTITUTO DE PESQUISA ECONÔMICA APLICADA. Desafios do Desenvolvimento. Brasília. Ipea, 2016. 
IPEA - INSTITUTO DE PESQUISA ECONÔMICA APLICADA. Atlas do Desenvolvimento. Brasília. Ipea, 2017.

KUJAWA, H. Conflitos territoriais envolvendo indígenas e agricultores: uma análise histórica e jurídica de políticas públicas contraditórias. Curitiba: CRV, 2015.

MONNERAT, G. L.; SOUZA, R. G. Da seguridade social à intersetorialidade: reflexões sobre a integração das políticas sociais no Brasil. Revista Katálysis, Florianópolis, v. 14, n. 1, p. 41-49, jan./jun. 2011.

MOTTA, F. Salada de Crianças: a roda de conversa como prática dialógica. In: CONGRESSO NACIONAL DE EDUCAÇÃO, 9.; CONGRESSO SUL BRASILEIRO DE PSICOPEDAGOGIA, 3., 2009, Curitiba. Anais... Curitiba: PUCPR, 2009. Disponível em: <http://www.pucpr.br/eventos/educere/educere2009/anais/pdf/2115_1035.pdf >. Acesso em: 2 jan. 2017.

ONU-BRASIL. Indígenas, negros e mulheres são mais afetados por pobreza e desemprego no Brasil, diz CEPAL. 2 nov. 2016. Disponível em:

$<$ https://nacoesunidas.org/indigenas-negros-e-mulheres-sao-mais-afetados-por-pobreza-edesemprego-no-brasil-diz-cepal/>. Acesso em: 6 ago. 2017.

PAIVA, B. A. (Org.). Sistema Único de Assistência Social em Perspectiva: direitos, política pública e superexploração. São Paulo: Veras, 2014.

PASSOS, E.; BARROS, R. B. de. A cartografia como método de pesquisa-intervenção. In: ; KASTRUP, V.; ESCÓSSIA, L. (Orgs.). Pistas do método da cartografia: pesquisaintervenção e produção de subjetividade. Porto Alegre: Sulina, 2009. p. 17-31.

PEREIRA, V. T.; GUARESCHI, P. Paradoxos da Assistência Social: algumas considerações. Textos \& Contextos, Porto Alegre, v. 12, n. 2, p. 383-391, jul./dez. 2013.

PRADO FILHO, K.; TETI, M. M. A cartografia como método para as ciências humanas e sociais. Barbarói, Santa Cruz do Sul, n. 38, p. 45-59, jan./jun. 2013.

SAWAIA, B. (Org.). As artimanhas da exclusão: análise psicossocial e ética da desigualdade social. 2. ed. Petrópolis: Vozes, 2001.

SILVA, M. B. Entre a rebeldia e o conformismo: o debate com os sujeitos demandatários da Política de Assistência Social. 2012. Tese (Doutorado em Serviço Social) - Pontifícia Universidade Católica do Rio Grande do Sul, Porto Alegre, 2012.

TEDESCO, S. H.; SADE, C.; CALIMAN, L. V. A entrevista na pesquisa cartográfica: a experiência do dizer. Fractal: Revista de Psicologia, Niterói, v. 25, n. 2, p. 299-322, maio/ago. 2013.

VIANNA, M. L. T. W. Americanização [Perversa] da seguridade social no Brasil: estratégias de bem-estar e políticas públicas. Rio de Janeiro: Revam; IUPERJ; UCAM, 1998.

YAZBEK, M. C. Classes subalternas e Assistência Social. São Paulo: Cortez, 1993. 
ZITZKE, L. O. Políticas públicas de desenvolvimento territorial e o enfrentamento da pobreza no território meio oeste contestado em Santa Catarina. 2011. 78. Monografia (Graduação em Engenharia Agrônoma) - Universidade Federal de Santa Catarina, Florianópolis, 2011.

\section{Sobre os autores}

Maria Carolina da Silveria Moesh é graduada em Psicologia. Programa de Mestrado Profissional em Políticas Sociais e Dinâmicas Regionais, ambos da Unochapecó. Endereço eletrônico: mariasilve@unochapeco.edu.br

Marcia Luiza Pit Dal Magro é docente no Programa de Mestrado Profissional em Políticas Sociais e Dinâmicas Regionais. Docente do Curso de Psicologia. Ambas da Unochapecó. Endereço eletrônico: mapit@ unochapeco.edu.br

Dunia Comerlatto é docente no Programa de Mestrado Profissional em Políticas Sociais e Dinâmicas Regionais da Universidade Comunitária da Região de Chapecó - Unochapecó. Endereço eletrônico: dunia@unochapeco.edu.br 